\title{
Analysis of the microRNA expression profiles of chicken dendritic cells in response to H9N2 avian influenza virus infection
}

\author{
Jing Yang ${ }^{1}$, Xinmei Huang ${ }^{1,2}$, Yuzhuo Liu' ${ }^{1}$, Dongmin Zhao ${ }^{1,2}$, Kaikai Han ${ }^{1,2}$, Lijiao Zhang ${ }^{1}$, Yin Li ${ }^{1,2}$ \\ and Qingtao Liu'1*
}

\begin{abstract}
MicroRNA (miRNA) plays a key role in virus-host interactions. Here, we employed deep sequencing technology to determine cellular miRNA expression profiles in chicken dendritic cells infected with H9N2 avian influenza virus (AIV). A total of 66 known and 36 novel miRNAs were differently expressed upon H9N2 infection, including 72 up-regulated and 30 down-regulated miRNAs. Functional analysis showed that the predicted targets of these miRNAs were significantly enriched in several pathways including endocytosis, notch, lysosome, p53, RIG-Ilike and NOD-like receptor signaling pathways. These data provide valuable information for further investigating the roles of miRNA in AIV pathogenesis and host defense response.
\end{abstract}

Keywords: H9N2 avian influenza virus, microRNA, chicken dendritic cell, pathogenesis, host defense response

\section{Introduction, methods and results}

H9N2 AIV has been circulating worldwide in multiple avian species and is endemic in poultry populations across Eurasia. On poultry farms, H9N2 AIV could result in a decrease in growth performance and egg production, and reduce the efficacy of vaccine interventions, and cause serious disease and even death with secondary infections of bacterial or viral pathogens [1,2]. Although great efforts have been made to develop intervention strategies to control H9N2 AIV infections in poultry, including a vaccination program with inactivated vaccines in China, H9N2 AIV outbreaks have continued to occur over the past two decades. Significantly, poultries have served as key intermediates in the transmission of

\footnotetext{
*Correspondence: taoqingliu2013@163.com

${ }^{1}$ Key Laboratory of Veterinary Biological Engineering and Technology

of Ministry of Agriculture, National Center for Engineering Research of Veterinary Bio-products, Institute of Veterinary Medicine, Jiangsu

Academy of Agricultural Sciences, 50 Zhongling Street, Nanjing 210014, Jiangsu, China

Full list of author information is available at the end of the article
}

AIV from avian species to humans, and H9N2 AIV has occasionally been transmitted from poultries to humans [1]. More seriously, H9N2 AIV has donated their internal genes to other subtype AIVs and facilitated the genesis of other emerging human-lethal AIVs, such as H5N1, H7N9, H10N8 and H5N6 AIVs [1]. Therefore, understanding the interaction mechanism between H9N2 AIVs and chickens is not only essential to the control of avian influenza in poultry, but also important for human health.

MiRNAs are non-coding RNAs with a length of about 22 nucleotides, and could regulate gene expression by base pairing with the $3^{\prime}$ - or $5^{\prime}$-UTR of the target mRNAs. They have been shown to be implicated in several cellular functions, including proliferation, differentiation, tumorigenesis, apoptosis, immune and inflammatory response, etc. An increasing number of studies showed that influenza virus infection can trigger changes of cellular miRNA profiles. For example, differential miRNA profiles were found in mouse lungs infected with the 1918 pandemic $\mathrm{H} 1 \mathrm{~N} 1$ and seasonal H1N1 influenza viruses

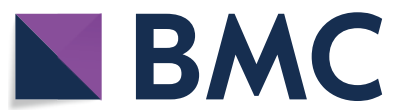

(c) The Author(s) 2020. This article is licensed under a Creative Commons Attribution 4.0 International License, which permits use, sharing, adaptation, distribution and reproduction in any medium or format, as long as you give appropriate credit to the original author(s) and the source, provide a link to the Creative Commons licence, and indicate if changes were made. The images or other third party material in this article are included in the article's Creative Commons licence, unless indicated otherwise in a credit line to the material. If material is not included in the article's Creative Commons licence and your intended use is not permitted by statutory regulation or exceeds the permitted use, you will need to obtain permission directly from the copyright holder. To view a copy of this licence, visit http://creativeco mmons.org/licenses/by/4.0/. The Creative Commons Public Domain Dedication waiver (http://creativecommons.org/publicdomain/ zero/1.0/) applies to the data made available in this article, unless otherwise stated in a credit line to the data. 
[3]. Another study revealed strain-specific host miRNA molecular signatures associated with the swine-origin H1N1 and avian-origin H7N7 influenza A virus in human A549 cells [4]. Differential miRNA expression profiles have been observed in chicken lungs during H5N3 AIV infection [5]. In addition, H9N2 AIV infection has been shown to activate the immune responses of mouse and avian dendritic cells by regulating the expression of miRNAs [6-8]. All of these studies suggest that miRNAs play an important role in the complex interactions occurring between influenza viruses and their hosts [9]. However, such studies of H9N2 AIV have focused on a very limited number of miRNAs using reverse transcription quantitative PCR (RT-qPCR) or traditional microarray analyses.

Dendritic cells (DCs) are able to sense invading viruses and play a key role in the host defense response to virus infection [10]. Upon encountering viral pathogens, DCs produce interferons (IFN) and other regulatory cytokines that contribute to the innate immune response, and then migrate to secondary lymphoid organs and present antigens to $\mathrm{T}$ cells to induce adaptive immune responses [10]. However, some viral pathogens can induce the dysregulation of DC function, which in turn influences immunological homeostasis and the clinical outcome of infection [11]. Since H9N2 AIV could influence the host response to vaccine and the outcome of secondary infections, it is necessary to study the interaction between DCs and H9N2 AIV. In this study, we determined the global miRNA expression profiles in chicken DCs during H9N2 AIV infection using deep sequencing technology for the first time, which may provide helpful insights into understanding the interaction between DCs and H9N2 AIV.

Chicken DCs were cultured from bone marrow cells with RPMI-1640 medium containing 5\% FBS (Wisent Bio Products, Canada), $50 \mathrm{ng} / \mathrm{mL}$ chicken GM-CSF (Abcam, USA) and $10 \mathrm{ng} / \mathrm{mL}$ IL-4 (Kingfisher, USA), as previously described [12]. To identify miRNA changes of DCs infected with H9N2 AIVs, two small RNA libraries were constructed in triplicates for H9N2 AIV-infected (A/ duck/Nanjing/06/2003 strain, with a multiplicity of infection of 5) and mock-infected DCs at $6 \mathrm{~h}$ post infection, and then were sequenced by Solexa technology on Illumina HiSeq XTen (Illumina, USA). Sequencing data have been submitted to the GEO database (accession number GSE147658). After removing low quality sequences, adapter sequences, and sequences smaller than $18 \mathrm{nt}$, 6.76-10.49 and 10.38-10.67 million clean reads were obtained from the virus and mock infected groups. The length distribution of the clean reads was similar in infection and mock libraries, and the majorities ranged from $22 \mathrm{nt}$ to $23 \mathrm{nt}$ in size (Additional file 1), which indicates the successful enrichment of mature miRNAs in the libraries of the two groups. These clean reads were then screened against the GenBank database and Rfam database, and more than $80 \%$ of the annotated small RNAs (miRNA, tRNA, rRNA, and other non-coding RNA) were categorised as miRNAs (Additional file 2). Next, these clean reads were aligned with chicken miRNAs in miRBase version 21.0 database, and 4.29-8.12 and 6.72-7.37 million clean reads were mapped to the known miRNA of chicken in H9N2 AIV and mock infected libraries respectively (Additional file 3). The rest reads, which were mapped to chicken genome, were further utilized to predict novel miRNAs using miRDeep2 software as described previously [13]. Finally, we identified 994 known and 9208 novel miRNAs in all libraries (Additional file 4).

To identify the differentially expressed miRNAs between H9N2 AIV-infected and mock-infected groups, the raw counts of miRNA reads were further normalized by transcripts per million reads (TPM), and the miRNA expression levels between the two groups were compared using the DESeq R package [14]. The estimated absolute $\log 2$-fold change of $>1$, and a corrected $\mathrm{p}$-value $<0.05$ were used as the thresholds for significant differently expressed genes. The results showed that 66 known and 36 novel miRNAs were significantly differentially expressed between the two groups (Table 1, Additional file 5). Of these miRNAs, 42 known and 30 novel miRNAs were up-regulated, and 24 known and 6 novel miRNAs genes were down-regulated following H9N2 AIV infection.

To understand the biological function of miRNAs during H9N2 AIV infection, 13503 target genes were predicted for the significantly differentially expressed (SDE) miRNAs using RNAhybrid and miRanda software [15], and one miRNA targeted many mRNA and vice versa (Additional file 6). GO enrichment analysis of the target genes showed that the SDE miRNAs were involved in the regulation of cellular process, protein modification process, MAPK cascade, response to stimulus, protein metabolic process, and other processes (Figure 1, Additional file 7). To analyze the roles of these SDE miRNA in regulatory networks, KEGG pathway analysis was also performed for the target genes. The results showed that these targets were mainly involved in endocytosis, notch signaling pathway, RIG-I-like receptor signaling pathway, lysosome, p53 signaling pathway, and NOD-like receptor signaling pathway (Figure 2, Additional file 8). These results indicate that the SDE miRNA may play a crucial role in regulating the cellular metabolic process, signal transduction and immune responses of DCs during H9N2 AIV infection.

To confirm the data obtained through RNA-seq analysis, the miRNAs were isolated from a replica RNA sequencing infection experiment using 
Table 1 Significantly differentially expressed known chicken miRNA in DCs induced by H9N2 AIV infection

\begin{tabular}{|c|c|c|c|c|c|}
\hline miRNA & $\begin{array}{l}\text { H9N2-infected DCs } \\
\text { (TPM) }\end{array}$ & $\begin{array}{l}\text { Mock-infected DCs } \\
\text { (TPM) }\end{array}$ & Fold change & $P$ value & Style \\
\hline gga-miR-302b-3p & 8.800102678 & 0.321066631 & 27.41 & $1.03 E-02$ & Up \\
\hline gga-miR-302d & 7.394757730 & 0.420683683 & 17.58 & $2.80 \mathrm{E}-02$ & Up \\
\hline gga-miR-551-5p & 16.17959332 & 0.963199892 & 16.79 & $2.76 \mathrm{E}-04$ & Up \\
\hline gga-miR-449c-5p & 30.39688718 & 2.132361815 & 14.26 & $7.23 \mathrm{E}-07$ & Up \\
\hline gga-miR-551-3p & 326.4538591 & 44.31762933 & 7.37 & $7.29 E-31$ & Up \\
\hline gga-miR-1666 & 15.19538833 & 2.457331401 & 6.18 & 7.86E-03 & Up \\
\hline gga-miR-187-3p & 166.0448253 & 30.56495477 & 5.43 & $1.19 \mathrm{E}-15$ & Up \\
\hline gga-miR-205b & 13.92136269 & 2.579163928 & 5.39 & $2.85 E-02$ & Up \\
\hline gga-miR-1467-3p & 223.8620766 & 49.12096621 & 4.56 & $6.74 \mathrm{E}-08$ & Up \\
\hline gga-miR-365-3p & 1805.885624 & 405.3167326 & 4.46 & $1.19 E-32$ & Up \\
\hline gga-miR-365b-5p & 894.8004725 & 206.3600374 & 4.34 & $2.42 \mathrm{E}-14$ & Up \\
\hline gga-miR-1708 & 14.70678182 & 3.420531293 & 4.29 & $4.00 \mathrm{E}-02$ & Up \\
\hline gga-miR-21-3p & 2753.261063 & 713.6833743 & 3.86 & $1.28 \mathrm{E}-30$ & Up \\
\hline gga-miR-190a-3p & 167.0188522 & 47.11513315 & 3.55 & $2.81 \mathrm{E}-08$ & Up \\
\hline gga-miR-190a-5p & 630.0087664 & 197.5629264 & 3.19 & $9.54 \mathrm{E}-17$ & Up \\
\hline gga-miR-7467-3p & 85.99901053 & 27.24794349 & 3.16 & $9.94 \mathrm{E}-06$ & Up \\
\hline gga-miR-200a-3p & 238.1628792 & 75.72797869 & 3.14 & $1.80 \mathrm{E}-11$ & Up \\
\hline gga-miR-193a-3p & 217.6650688 & 71.21556278 & 3.06 & $1.03 E-05$ & Up \\
\hline gga-miR-3535 & 274.4292255 & 91.00293488 & 3.02 & $1.33 \mathrm{E}-11$ & Up \\
\hline gga-miR-29b-3p & 86081.05620 & 29667.27626 & 2.90 & $2.39 E-21$ & Up \\
\hline gga-miR-103-1-5p & 72.87844804 & 25.41928950 & 2.87 & $2.80 E-02$ & Up \\
\hline gga-miR-7467-5p & 92.88247498 & 32.45298254 & 2.87 & $5.38 \mathrm{E}-06$ & Up \\
\hline gga-miR-22-5p & 10483.71708 & 3915.882453 & 2.68 & $2.26 \mathrm{E}-17$ & Up \\
\hline gga-miR-451 & 5731.056244 & 2160.176030 & 2.65 & 1.05E-04 & Up \\
\hline gga-miR-20a-5p & 40364.26188 & 15575.49639 & 2.59 & $8.40 E-12$ & Up \\
\hline gga-miR-155 & 26783.80295 & 10737.39804 & 2.49 & $1.19 \mathrm{E}-15$ & Up \\
\hline gga-miR-1434 & 685.0883524 & 276.4517753 & 2.48 & $5.54 \mathrm{E}-09$ & Up \\
\hline gga-miR-7 & 1759.477832 & 751.2428887 & 2.34 & $2.98 \mathrm{E}-11$ & Up \\
\hline gga-miR-429-3p & 326.3798282 & 139.7225717 & 2.34 & $3.99 \mathrm{E}-08$ & Up \\
\hline gga-miR-200b-3p & 125.0793544 & 53.86359132 & 2.32 & $5.96 \mathrm{E}-05$ & Up \\
\hline gga-miR-29a-5p & 571.6283718 & 250.7912729 & 2.28 & $3.55 \mathrm{E}-09$ & Up \\
\hline gga-miR-15b-5p & 13909.71515 & 6196.684286 & 2.24 & $1.77 \mathrm{E}-12$ & Up \\
\hline gga-miR-33-5p & 4032.377244 & 1814.920557 & 2.22 & $1.59 \mathrm{E}-10$ & Up \\
\hline gga-miR-215-5p & 266.1401100 & 121.3765857 & 2.19 & $6.69 \mathrm{E}-07$ & Up \\
\hline gga-miR-101-2-5p & 632.9850972 & 292.6375455 & 2.16 & $3.96 \mathrm{E}-08$ & Up \\
\hline gga-miR-32-5p & 2061.528955 & 955.6190685 & 2.16 & $1.35 E-10$ & Up \\
\hline gga-miR-153-3p & 206.7604279 & 95.94182016 & 2.16 & $7.22 \mathrm{E}-04$ & Up \\
\hline gga-miR-181b-5p & 10563.99373 & 4909.109999 & 2.15 & $3.30 \mathrm{E}-06$ & Up \\
\hline gga-miR-30e-5p & 39176.41147 & 18594.68260 & 2.11 & 4.17E-08 & Up \\
\hline gga-miR-15a & 24351.55946 & 11588.38769 & 2.11 & $8.35 E-11$ & Up \\
\hline gga-miR-22-3p & 37910.33000 & 18564.17097 & 2.04 & $1.59 \mathrm{E}-10$ & Up \\
\hline gga-miR-181a-5p & 34649.54269 & 17283.22335 & 2.00 & $5.70 \mathrm{E}-08$ & Up \\
\hline gga-miR-6594-5p & 94.67578132 & 197.5792320 & -2.09 & $5.89 \mathrm{E}-05$ & Down \\
\hline gga-miR-6642-5p & 23.43620583 & 52.39678050 & -2.24 & $2.11 \mathrm{E}-02$ & Down \\
\hline gga-miR-19b-5p & 464.0802376 & 1045.118019 & -2.25 & $2.03 E-11$ & Down \\
\hline gga-miR-6556-3p & 43.50229656 & 101.8832443 & -2.34 & $2.50 \mathrm{E}-04$ & Down \\
\hline gga-miR-1712-5p & 24.56364507 & 57.59468264 & -2.34 & $1.11 \mathrm{E}-02$ & Down \\
\hline gga-miR-6696-3p & 55.97845749 & 136.4756894 & -2.44 & $1.04 \mathrm{E}-02$ & Down \\
\hline gga-miR-1559-3p & 571.3932734 & 1401.389558 & -2.45 & $2.33 E-13$ & Down \\
\hline
\end{tabular}


Table 1 (continued)

\begin{tabular}{|c|c|c|c|c|c|}
\hline miRNA & $\begin{array}{l}\text { H9N2-infected DCs } \\
\text { (TPM) }\end{array}$ & $\begin{array}{l}\text { Mock-infected DCs } \\
\text { (TPM) }\end{array}$ & Fold change & $P$ value & Style \\
\hline gga-miR-15b-3p & 53.47288137 & 134.9119737 & -2.52 & $5.41 \mathrm{E}-06$ & Down \\
\hline gga-miR-1759-3p & 15.33179667 & 41.36731788 & -2.70 & $1.02 \mathrm{E}-02$ & Down \\
\hline gga-miR-130b-3p & 7672.726337 & 21287.07056 & -2.77 & $9.60 \mathrm{E}-18$ & Down \\
\hline gga-let-7a-2-3p & 19.28809129 & 53.87717145 & -2.79 & $1.44 \mathrm{E}-03$ & Down \\
\hline gga-miR-34c-5p & 7.702176123 & 23.13412006 & -3.00 & $4.81 \mathrm{E}-02$ & Down \\
\hline gga-miR-365-2-5p & 15.08675579 & 53.42821336 & -3.54 & $3.28 \mathrm{E}-04$ & Down \\
\hline gga-miR-15c-3p & 5.398144233 & 20.51538185 & -3.80 & $2.33 \mathrm{E}-02$ & Down \\
\hline gga-miR-92-5p & 82.93267399 & 316.4139231 & -3.82 & $2.53 E-14$ & Down \\
\hline gga-miR-193b-5p & 5.710651656 & 22.56361416 & -3.95 & $1.15 \mathrm{E}-02$ & Down \\
\hline gga-miR-184-3p & 4.083834071 & 16.96911507 & -4.16 & $4.11 \mathrm{E}-02$ & Down \\
\hline gga-let-7b & 141.4738821 & 623.2702767 & -4.41 & $3.18 \mathrm{E}-26$ & Down \\
\hline gga-miR-128-1-5p & 26.18173380 & 119.0613949 & -4.55 & $6.81 \mathrm{E}-11$ & Down \\
\hline gga-miR-31-3p & 6.390196622 & 33.92087134 & -5.31 & $1.95 E-04$ & Down \\
\hline gga-miR-6575-3p & 3.409378134 & 20.08863924 & -5.89 & $2.31 \mathrm{E}-02$ & Down \\
\hline gga-miR-1591-3p & 1.921727259 & 11.45189329 & -5.96 & $3.79 E-02$ & Down \\
\hline gga-miR-31-5p & 70.91080554 & 448.1771463 & -6.32 & $1.54 \mathrm{E}-12$ & Down \\
\hline gga-miR-1702 & 19.45910134 & 203.4676260 & -10.46 & $1.20 \mathrm{E}-07$ & Down \\
\hline
\end{tabular}

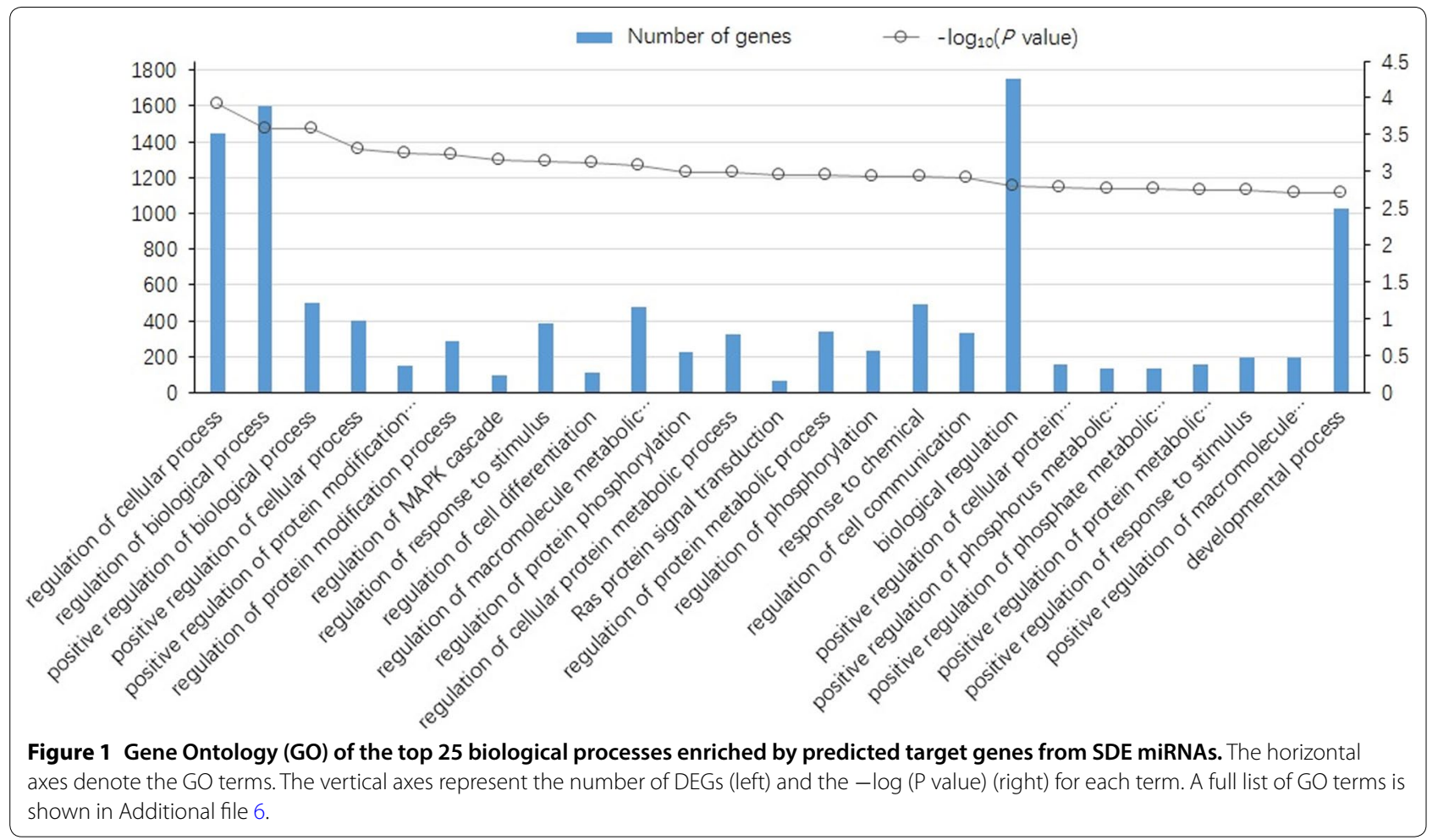

miRNA isolation kit (TIANGEN, China). The isolated miRNAs were first polyadenylated with polyA polymerase and then were reverse transcribed into complementary DNA (cDNA) with a poly $(\mathrm{T})$ adapter primer (TIANGEN, China). Ten SDE miRNAs were selected for validation by quantitative reverse transcription PCR (qRT-PCR) using the miRNA qPCR SYBR Green Detection Kit (TIANGEN, China). The 


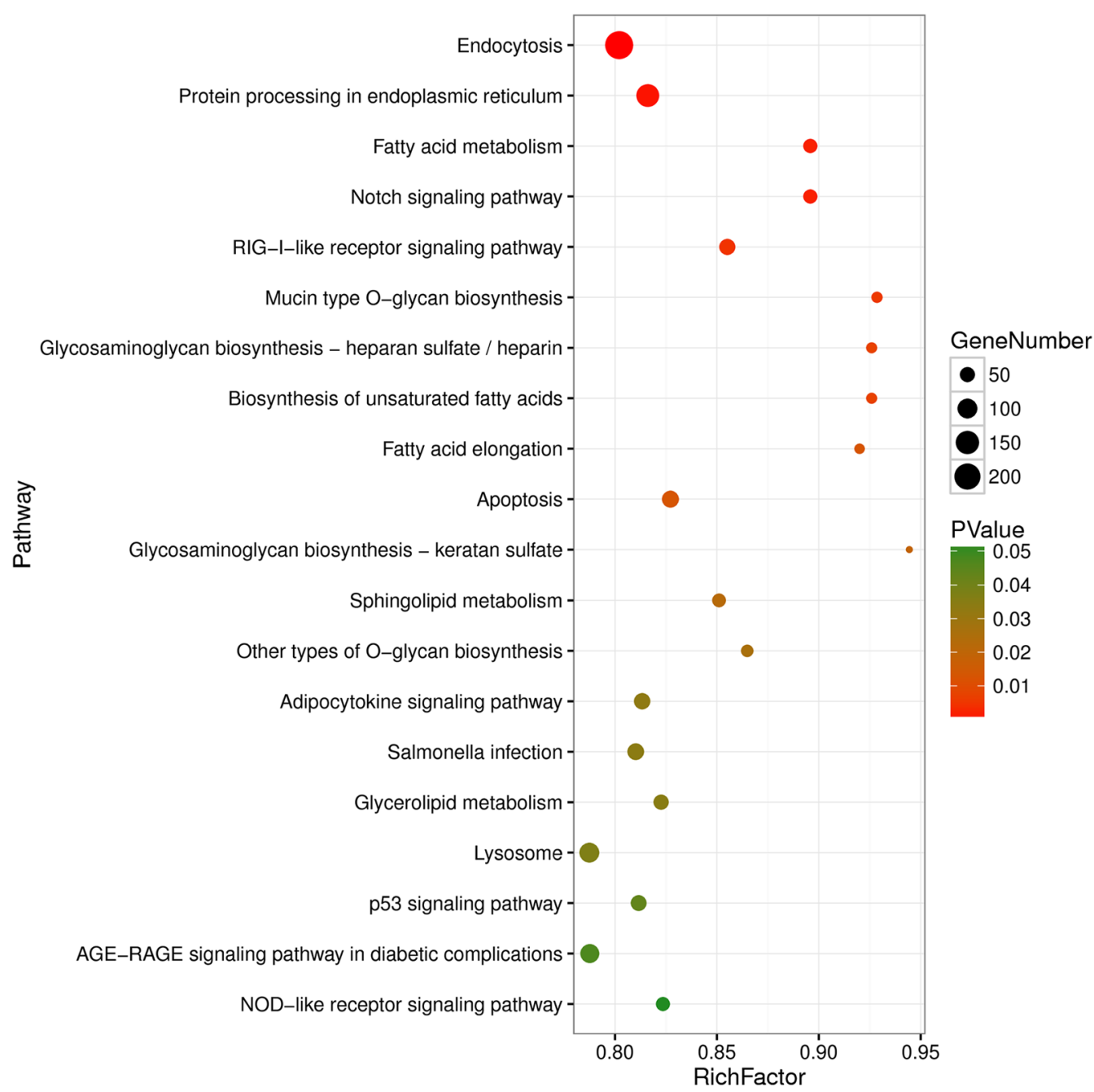

Figure 2 Top 20 KEGG pathways enriched by predicted target genes from SDE miRNAs. The color scale and the circle on the right-hand side illustrate the significant level and target gene number of the indicated pathway. A full list of pathways is shown in Additional file 7.

miRNA-specific forward primers used in this study are shown in Additional file 9. The results confirmed the up-regulation of five known and one novel miRNAs, and the down-regulation of three known and one novel miRNAs in H9N2 AIV-infected DCs compared with the mock cells (Figure 3A). The results of qRT-PCR were consistent with the data obtained from RNA-seq, although larger fold change values were obtained from qPCR for some selected miRNAs.

Finally, eight target mRNAs for the 10 SDE miRNAs were also selected for qRT-PCR analysis (Figure 3B). The results showed that SUMF1, CTBP1, NOD1, and CTNS were down-regulated, and S1PR3, DLL1, and FGF5 were up-regulated, which was inversely correlated with the expression of their miRNAs (Figure 3C). However, the expression of other one gene (RAB2A) was positively correlated with the expression of their miRNAs.

\section{Discussion}

In recent years, high-throughput sequencing technology has been effectively used to identify differentially expressed miRNAs, on a genome-wide scale, during viral infection. Increasing studies showed that miRNAs, as ubiquitous regulators of gene expression, play an important regulatory role in virus-host interactions. Nevertheless, the roles of miRNA in the regulation of host responses to H9N2 AIV infection in chicken DCs are poorly understood. In the present study, highthroughput sequencing approach was subjected to identify differentially expressed miRNAs in chicken DCs in response to H9N2 AIV infection. A total of 66 known and 36 novel differentially expressed miRNAs 


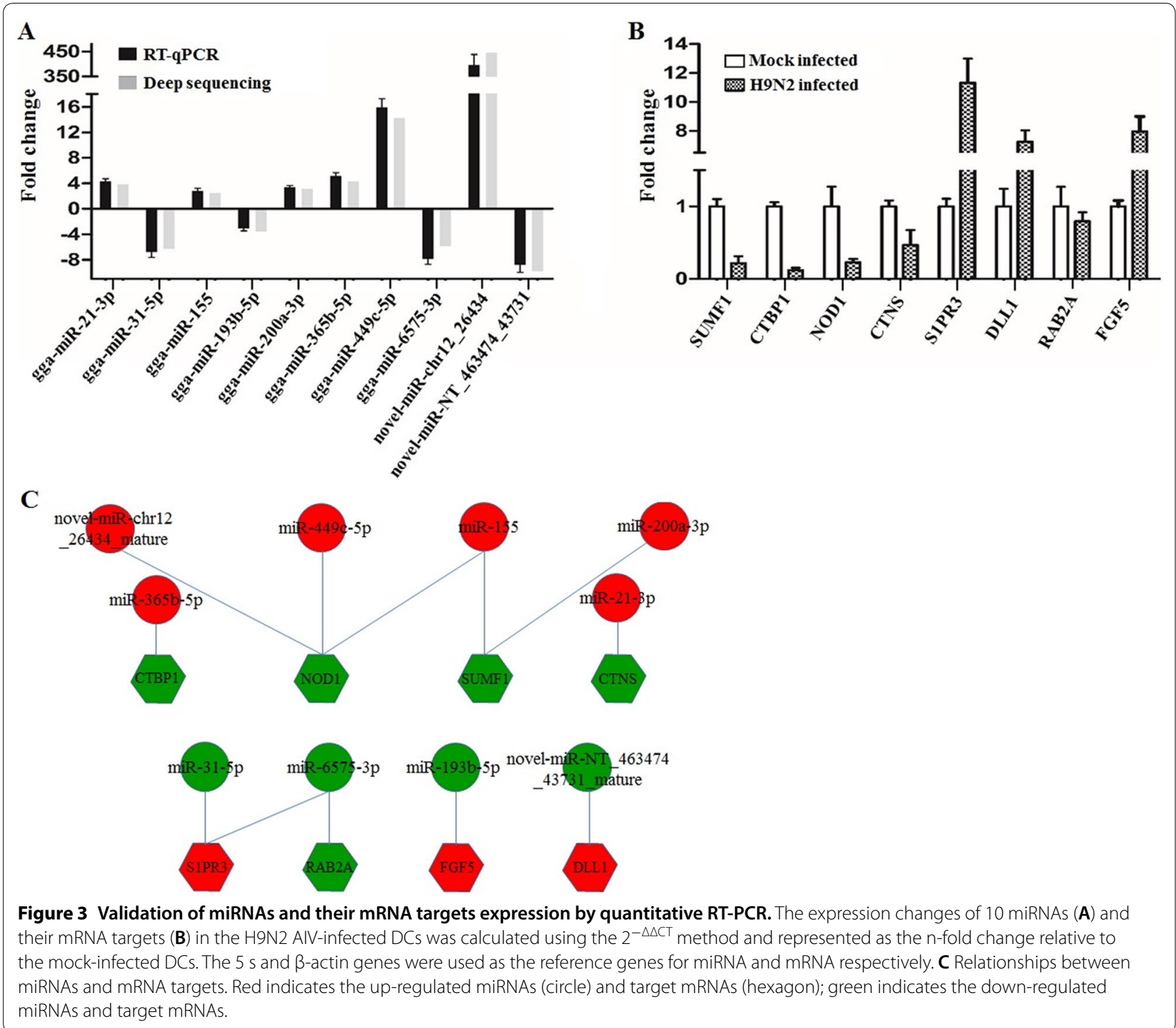

were identified successfully. Among these 66 know SDE miRNAs, 12 miRNAs (miR-22-3p, miR-22-5p, miR-30e-5p, miR-31-5p, miR-32-5p, miR-33-5p, miR92-5p, miR-155, miR-184-3p, miR-215-5p, miR-451 and let-7b) are also found to be differentially expressed in chicken lungs, immune organs, and embryo fibroblasts during H5N3, H5N1 and H9N2 AIV infection [5, 16, 17]. In addition, another 7 know SDE miRNAs (miR7, miR-21-3p, miR-34c-5p, miR-187-3p, miR-200a-3p, miR-429-3p and miR-1434) are identified in other virus infected chickens [18-20]. Therefore, these DE miRNAs might play a vital role in the interaction between chicken DCs and H9N2 AIV.

The innate immune responses are the first line of host defense against virus infection. Emerging data have showed some miRNAs can inhibit or promote virus replication by regulating host innate immune responses. Several of the SDE miRNAs identified in this study can target genes that are associated with immune responses. It has been reported that miR-7 is widely conserved in animal species and is up-regulated during invertebrates and vertebrate's virus infection, such as poliovirus and white spot syndrome virus (WSSV). In crab, the miR-7 could inhibit host anti-viral immune response by targeting Myd88 to enhance WSSV replication [21], whereas the miR-7 upregulation induced the inhibition of poliovirus infection in human cells [22]. Similarly, miR-7 was also found to be up-regulated in human influenza virus infection [23] and in H9N2 AIV infection in this study. Additionally, miR21-3p has been found to be down-regulated during H5N1 
AIV and 2009 pandemic H1N1 influenza virus infection and could promote influenza virus replication by repressing the expression of HDAC8 gene in A549 cells [24]. But, the miR-21-3p was found to be up-regulated in chicken DCs during H9N2 virus infection in the present study. Therefore, the role of miR-7 and miR-21-3p in H9N2 virus infection needs to be further studied.

In addition, two DE miRNAs, miR-155 and miR130b-3p, identified in this study have been reported to have an antiviral activity in chicken cells. As one of the widely studied miRNAs, miR-155 is generally believed to be a multifunctional miRNA and plays a critical role in cancer, immune and inflammation response, and viral infection. It was reported that miR-155 is required for the function of B and T lymphocytes and dendritic cells [25], and the induction of this microRNA negatively modulates host innate immune responses and suppresses Japanese encephalitis virus replication in human microglial cells [26]. However, miR-155 was found to suppress the TLR3 expression in chicken embryo fibroblast cells and HD11 cells [27], and contributed to the increased susceptibility to Marek's disease in chickens [28]. However, other studies showed that the miR-155 enhanced type I interferon expression via targeting SOCS1 and TANK, and suppresses infectious bursal disease virus replication in DF1 cells [29]. The miR-130b-3p belongs to the miR$130 / 301$ family and has been found to take part in the regulation of cytokine expression. A recent study showed that the miR-130b-3p could target socs5 to enhance the expression of STAT in chicken DF1 cells, which contributes to the increase of IFN- $\beta$ and, further suppresses the replication of infectious bursal disease virus [30]. Therefore, it is worth for further study whether these microRNAs play a regulatory role in H9N2 AIV infection via regulating host innate immune response.

Some miRNAs are able to target multiple mRNAs, which may be involved in the regulation of multiple cell processes. GO enrichment analysis of the potential targeted genes showed that these DE miRNAs are mainly involved in the regulation of metabolic process, signal transduction and immune response (Additional file 6). The KEGG pathway analysis showed that DE miRNAs are involved in the regulation of endocytosis, Notch signaling pathway, RIG-I like receptor signaling pathway, lysosome, p53 signaling pathway, and other pathways (Additional file 7). The Notch signaling pathway is known as a well-conserved throughout metazoans, and plays a fundamental role during embryonic development that is associated with cell fate determination, and immune regulation. It is known that various viruses can exploit the Notch signaling pathway to regulate viral replication and affect the fate of infected cells. In human, HIV could inactivate Notch signaling to result in the inhibition of KSHV lytic replication and the induction of pro-proliferative and -survival cytokines, such as IL-2 and TIMP-1 [31]. Conversely, influenza virus infection activated Notch signaling by up-regulating the Notch ligand Delta-like 1 expression in mice macrophages, and blocking of Notch signaling led to higher virus load with an impaired production of IFN- $\gamma$ in mice lungs [32]. Although the Notch signaling pathway has been reported to be involved in regulation of cell proliferation and differentiation in chickens [33], there are no reports about the effects of this pathway in virus infection in chickens. Therefore, further work is required to determine the specific roles of Notch signaling in the interaction between H9N2 virus and chicken DCs. Lysosomes are acidic and hydrolytic organelles within cells, which are known primarily to degrade macromolecules or infected pathogens delivered by endocytosis, phagocytosis, and autophagy, and play vital roles in innate immunity recognition, antigen presentation, and pathogen elimination [34, 35]. In the current study, 100 genes of the lysosome pathway were predicted to be targeted by $91 \mathrm{DE}$ miRNAs. These results suggested that these miRNAs might be involved in the regulation of the innate immune response and antigen presentation functions of DCs by targeting the lysosome pathway during H9N2 infection.

In summary, the miRNA expression profiles in chicken DCs upon H9N2 AIV infection was evaluated by deep sequencing. A total of 66 known differentially expressed miRNAs and 36 novel miRNA candidates were identified, supporting the point that certain miRNAs are essential in host and virus interaction. Target prediction and functional analysis showed that these miRNAs may be involved in the regulation of host defense response and viral replication during H9N2 AIV infection. However, further research is needed to investigate the specific role of these miRNAs during H9N2 infection in DCs.

\section{Supplementary information}

Supplementary information accompanies this paper at https://doi. org/10.1186/s13567-020-00856-z.

Additional file 1. Length distribution of the clean reads in libraries from H9N2-infected and mock-infected DCs. The majority of the small RNAs in all libraries were at 22-23 nt. M: mock-infected DCs; V: H9N2 AIVinfected DCs.

Additional file 2. Pie charts of small RNAs percentages in libraries from H9N2-infected and mock-infected DCs. More than $80 \%$ of the annotated small RNAs in all libraries were miRNAs. M: mock-infected DCs; V: H9N2 AIV-infected DCs.

Additional file 3. Summary of small RNAs sequencing data. M: mockinfected DCs; V: H9N2 AIV-infected DCs.

Additional file 4. MiRNA profile of H9N2-infected and mock-infected DCs. In total, 994 known and 9208 novel miRNAs were identified in all samples. 
Additional file 5. Significantly differentially expressed (SDE) novel chicken miRNA in DCs induced by H9N2 AIV infection. Thirty-six novel miRNAs were found to be significantly differentially expressed between H9N2-infected and mock-infected DCs

Additional file 6. Predicted targets for SDE miRNAs. Using RNAhybrid and miRanda software, 13503 target genes were predicted for SDE miRNAs, and one mRNA was targeted by many miRNAs and vice versa.

Additional file 7. GO terms for biological process enriched by the predicted target genes from SDE miRNAs. GO enrichment analysis revealed 180 biological processes were significantly ( $p$-value $<0.05$ ) enriched by target genes, and the 27 terms associated with immune responses were marked in bold.

\section{Additional file 8. KEGG pathway annotations for the predicted target genes from SDE miRNAs.}

Additional file 9. Primers used to detect miRNA and target mRNA expression levels with quantitative RT-PCR.

\section{Abbreviations}

AlV: avian influenza; cDNA: complementary DNA; DCs: dendritic cells; IFN: interferons; miRNA: microRNA; qRT-PCR: quantitative reverse transcription PCR; SDE: significantly differentially expressed; TPM: transcripts per million reads; WSSV: white spot syndrome virus.

\section{Acknowledgements}

The authors wish to thank Jingying Li for her care and handling of the animals.

\section{Authors' contributions}

The experiment was conceived and designed by $Q T$ and $Y L$. JY, XH and $Y L$ performed the RNA-seq experiments and analyzed the data. DZ, KH and LZ performed the viral infection and quantitive RT-PCR experiments. QT and JY wrote the manuscript. All authors read and approved the final manuscript.

\section{Funding}

This research was founded by the National Natural Science Funds of China (31972691 and 31502100), and the Jiangsu Agricultural Science and Technology Innovation Fund [CX (18)3017].

\section{Availability of data and materials}

Sequences were deposited at NCBI GEO repository with Accession Number GSE147658.

\section{Ethics approval and consent to participate}

All procedures involving animals were approved by the Committee on the Ethics of Animal Experiments of Jiangsu Academy of Agricultural Sciences (JAAS no. 20160203), and complied with the guidelines provided by the Jiangsu Province Animal Regulations (Government Decree no. 45).

\section{Consent to publish}

Not applicable.

\section{Competing interests}

The authors declare that they have no competing interests.

\section{Author details}

${ }^{1}$ Key Laboratory of Veterinary Biological Engineering and Technology of Ministry of Agriculture, National Center for Engineering Research of Veterinary Bio-products, Institute of Veterinary Medicine, Jiangsu Academy of Agricultural Sciences, 50 Zhongling Street, Nanjing 210014, Jiangsu, China. ${ }^{2}$ Jiangsu University, Zhenjiang, China.

Received: 4 May 2020 Accepted: 30 September 2020

Published online: 17 October 2020

\section{References}

1. Gu M, Xu L, Wang X, Liu X (2017) Current situation of H9N2 subtype avian influenza in China. Vet Res 48:49

2. Nili H, Asasi K (2002) Natural cases and an experimental study of H9N2 avian influenza in commercial broiler chickens of Iran. Avian Pathol. 31:247-252

3. Li Y, Chan EY, Li J, Ni C, Peng X, Rosenzweig E, Tumpey TM, Katze MG (2010) MicroRNA expression and virulence in pandemic influenza virusinfected mice. J Virol 84:3023-3032

4. Loveday EK, Svinti V, Diederich S, Pasick J, Jean F (2012) Temporal- and strain-specific host microRNA molecular signatures associated with swine-origin H1N1 and avian-origin H7N7 influenza A virus infection. J Virol 86:6109-6122

5. Wang Y, Brahmakshatriya V, Lupiani B, Reddy SM, Soibam B, Benham AL, Gunaratne P, Liu HC, Trakooljul N, Ing N, Okimoto R, Zhou H (2012) Integrated analysis of microRNA expression and mRNA transcriptome in lungs of avian influenza virus infected broilers. BMC Genomics. 13:278

6. Lin J, Xia J, Chen Y, Zhang K, Zeng Y, Yang Q (2017) H9N2 avian influenza virus enhances the immune responses of BMDCs by down-regulating miR29c. Vaccine. 35:729-737

7. Lin J, Xia J, Tu C, Zhang K, Zeng Y, Yang Q (2017) H9N2 avian influenza virus protein PB1 enhances the immune responses of bone marrowderived dendritic cells by down-regulating miR375. Front Microbiol. 8:287

8. Lin J, Xia J, Zhang T, Zhang K, Yang Q (2018) Genome-wide profiling of microRNAs reveals novel insights into the interactions between H9N2 avian influenza virus and avian dendritic cells. Oncogene 37:4562-4580

9. Ma Y, Ouyang J, Wei J, Maarouf M, Chen J (2016) Involvement of host noncoding RNAs in the pathogenesis of the influenza virus. Int J Mol Sci 18:39

10. Worbs T, Hammerschmidt SI, Forster R (2017) Dendritic cell migration in health and disease. Nat Rev Immunol 17:30-48

11. Rinaldo CR Jr, Piazza P (2004) Virus infection of dendritic cells: portal for host invasion and host defense. Trends Microbiol 12:337-345

12. Wu Z, Rothwell L, Young JR, Kaufman J, Butter C, Kaiser P (2010) Generation and characterization of chicken bone marrow-derived dendritic cells. Immunology 129:133-145

13. Friedlander MR, Mackowiak SD, Li N, Chen W, Rajewsky N (2012) miRDeep2 accurately identifies known and hundreds of novel microRNA genes in seven animal clades. Nucleic Acids Res 40:37-52

14. Anders S, Huber W (2010) Differential expression analysis for sequence count data. Genome Biol 11:R106

15. Rajewsky N (2006) microRNA target predictions in animals. Nat Genet 38(Suppl):S8-S13

16. Li Z, Zhang J, Su J, Liu Y, Guo J, Zhang Y, Lu C, Xing S, Guan Y, Li Y, Sun B, Zhao Z (2015) MicroRNAs in the immune organs of chickens and ducks indicate divergence of immunity against $\mathrm{H} 5 \mathrm{~N} 1$ avian influenza. FEBS Lett 589:419-425

17. Peng X, Gao QS, Zhou L, Chen ZH, Lu S, Huang HJ, Zhan CY, Xiang M (2015) MicroRNAs in avian influenza virus H9N2-infected and noninfected chicken embryo fibroblasts. Genet Mol Res 14:9081-9091

18. Li ZJ, Zhang YP, Li Y, Zheng HW, Zheng YS, Liu CJ (2014) Distinct expression pattern of miRNAs in Marek's disease virus infected-chicken splenic tumors and non-tumorous spleen tissues. Res Vet Sci 97:156-161

19. Yang X, Gao W, Liu H, Li J, Chen D, Yuan F, Zhang Z, Wang H (2017) MicroRNA transcriptome analysis in chicken kidneys in response to differing virulent infectious bronchitis virus infections. Arch Virol 162:3397-3405

20. Gao S, Jiang H, Sun J, Diao Y, Tang Y, Hu J (2019) Integrated analysis of miRNA and mRNA expression profiles in spleen of specific pathogen-free chicken infected with avian reticuloendotheliosis virus strain SNV. Int J Mol Sci 20:1041

21. Huang Y, Wang W, Xu Z, Pan J, Zhao Z, Ren Q (2018) Eriocheir sinensis microRNA-7 targets crab Myd88 to enhance white spot syndrome virus replication. Fish Shellfish Immunol 79:274-283

22. Zhang $X$, Liu D, Zhang S, Wei $X$, Song J, Zhang Y, Jin M, Shen Z, Wang X, Feng Z, Li J (2015) Host-virus interaction: the antiviral defense function of small interfering RNAs can be enhanced by host microRNA-7 in vitro. Sci Rep 5:9722

23. Buggele WA, Johnson KE, Horvath CM (2012) Influenza A virus infection of human respiratory cells induces primary microRNA expression. J Biol Chem 287:31027-31040 
24. Xia B, Lu J, Wang R, Yang Z, Zhou X, Huang P (2018) miR-21-3p regulates influenza $A$ virus replication by targeting histone deacetylase-8. Front Cell Infect Microbiol 8:175

25. Rodriguez A, Vigorito E, Clare S, Warren MV, Couttet P, Soond DR, van Dongen S, Grocock RJ, Das PP, Miska EA, Vetrie D, Okkenhaug K, Enright AJ, Dougan G, Turner M, Bradley A (2007) Requirement of bic/microRNA-155 for normal immune function. Science 316:608-611

26. Pareek S, Roy S, Kumari B, Jain P, Banerjee A, Vrati S (2014) MiR-155 induction in microglial cells suppresses Japanese encephalitis virus replication and negatively modulates innate immune responses. J Neuroinflammation 11:97

27. Hu X, Ye J, Qin A, Zou H, Shao H, Qian K (2015) Both microRNA-155 and virus-encoded MiR-155 ortholog regulate TLR3 expression. PLoS One 10:e0126012

28. Mitra A, Luo J, He Y, Gu Y, Zhang H, Zhao K, Cui K, Song J (2015) Histone modifications induced by MDV infection at early cytolytic and latency phases. BMC Genomics 16:311

29. Wang B, Fu M, Liu Y, Wang Y, Li X, Cao H, Zheng SJ (2018) gga-miR-155 enhances type I interferon expression and suppresses infectious burse disease virus replication via targeting SOCS1 and TANK. Front Cell Infect Microbiol 8:55

30. Fu M, Wang B, Chen X, He Z, Wang Y, Li X, Cao H, Zheng SJ (2017) MicroRNA gga-miR-130b suppresses infectious bursal disease virus replication via targeting of the viral genome and cellular suppressors of cytokine signaling 5. J Virol 92:e01646
31. Yan Q, Zhao R, Shen C, Wang F, Li W, Gao SJ, Lu C (2018) Upregulation of microRNA 711 mediates HIV-1 Vpr promotion of Kaposi's Sarcomaassociated herpesvirus latency and induction of pro-proliferation and pro-survival cytokines by targeting the notch/NF-kappaB-signaling axis. J Virol 92:e00580

32. Ito T, Allen RM, Carson WF, Schaller M, Cavassani KA, Hogaboam CM, Lukacs NW, Matsukawa A, Kunkel SL (2011) The critical role of Notch ligand Delta-like 1 in the pathogenesis of influenza A virus ( $\mathrm{H} 1 \mathrm{~N} 1)$ infection. PLoS Pathog 7:e1002341

33. Matsuda Y, Wakamatsu Y, Kohyama J, Okano H, Fukuda K, Yasugi S (2005) Notch signaling functions as a binary switch for the determination of glandular and luminal fates of endodermal epithelium during chicken stomach development. Development 132:2783-2793

34. Luzio JP, Pryor PR, Bright NA (2007) Lysosomes: fusion and function. Nat Rev Mol Cell Biol 8:622-632

35. McGourty K, Thurston TL, Matthews SA, Pinaud L, Mota LJ, Holden DW (2012) Salmonella inhibits retrograde trafficking of mannose-6-phosphate receptors and lysosome function. Science 338:963-967

\section{Publisher's Note}

Springer Nature remains neutral with regard to jurisdictional claims in published maps and institutional affiliations.
Ready to submit your research? Choose BMC and benefit from:

- fast, convenient online submission

- thorough peer review by experienced researchers in your field

- rapid publication on acceptance

- support for research data, including large and complex data types

- gold Open Access which fosters wider collaboration and increased citations

- maximum visibility for your research: over $100 \mathrm{M}$ website views per year

At BMC, research is always in progress.

Learn more biomedcentral.com/submissions 